\title{
Mercado de trabajo transfronterizo México- Guatemala: una construcción desde la experiencia de los trabajadores
}

\author{
Mexico-Guatemala cross-border labor market: a \\ construction from the experience of the workers
}

Recibido el 24 de abril de 2020.

Aceptado el 28 de agosto de 2020.

Publicado el 10 de septiembre de 2020.

${ }^{*}$ Autora para correspondencia: Jéssica Natalia Nájera-Aguirre. Correo electrónico: jnajera@colmex.mx

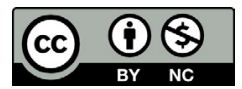

Esta obra está protegida bajo una Licencia Creative Commons Atribución-NoComercial 4.0 Internacional.

\author{
Jéssica Natalia Nájera-Aguirre ${ }^{\text {a* }}$ (1) https://orcid.org/0000-0003-1995-0578 \\ ${ }^{a}$ El Colegio de México, Centro de Estudios Demográficos, Urbanos y Ambientales, Ciudad de \\ México, México, correo electrónico: jnajera@colmex.mx
}

\section{Resumen}

El objetivo de este trabajo es fundar la estructura y funcionamiento del mercado laboral local transfronterizo entre la región de Chiapas del Soconusco y el suroeste de Guatemala, a partir de una construcción "desde abajo", basada en la experiencia vivida por trabajadores guatemaltecos entrevistados. La perspectiva transfronteriza, económica y poblacional fue la guía para vincular la oferta y la demanda de trabajadores, y los lugares de origen y destino laboral, como una forma de evitar el nacionalismo metodológico. La construcción de conocimiento desde la vida cotidiana permitió visibilizar la diversidad de los actores participantes, así como la conexión entre las necesidades de los trabajadores y los empleadores, las redes laborales transfronterizas (formales e informales) y las posibilidades de cruce, estancia y trabajo remunerado en el país vecino. El mercado laboral transfronterizo aquí detallado permite considerar nuevos escenarios a la luz de la reciente llegada de inmigrantes extranjeros a la región.

Palabras clave: mercado laboral, frontera, trabajadores, guatemaltecos, Chiapas.

\begin{abstract}
The objective of this work is to build the structure and functioning of the local cross-border labor market between the Soconusco region (Chiapas) and the southwest of Guatemala, from a construction "from below", based on the experience lived by interviewed Guatemalan workers. The cross-border, economic and population perspective was the guide to link the supply and demand of workers, and the places of origin and work destination, to avoid methodological nationalism. The construction of knowledge from daily life allowed to make visible the diversity of the participating actors, as well as the connection between the needs of workers and employers, cross-border labor networks (formal and informal) and the possibilities of crossing, staying and paid work in
\end{abstract}

CÓMO CITAR: Nájera-Aguirre, J. N. (2020). Mercado de trabajo transfronterizo México-Guatemala: una construcción desde la experiencia de los trabajadores. [Mexico-Guatemala cross-border labor market: a construction from the experience of the workers]. Estudios Fronterizos, 21, e055. https://doi.org/10.21670/ref.2013055 
the neighboring country. The cross-border labor market detailed allows considering new scenarios considering the recent arrival of foreign immigrants to the region.

Keywords: labor market, border, workers, Guatemalans, Chiapas.

\section{Introducción}

En la frontera México-Guatemala, específicamente en la región de co-frontera ${ }^{1}$ formada por la región del Soconusco en Chiapas ${ }^{2}$ y los departamentos del suroccidente guatemalteco, ${ }^{3}$ cada año se registra un promedio de 277000 cruces de trabajadores guatemaltecos que laboran en territorio mexicano - estimación propia con base en la Encuesta sobre Migración en la Frontera Sur de México (Emif Sur) de El Colegio de la Frontera Norte (El Colef) y colaboradores (El Colef et al., 2018). ${ }^{4}$ La movilidad laboral de guatemaltecos al Soconusco es histórica, proviene de una relación laboral entre empleadores extranjeros y nacionales del lado chiapaneco, y trabajadores guatemaltecos originada desde finales del siglo xix con la instalación de las primeras fincas cafetaleras en la región (Bartra, 1995). La demanda de mano de obra agrícola iniciada en aquella época ha persistido por las grandes fincas cafetaleras del Soconusco, como Irlanda, Hamburgo, Argovia, Germania, entre otras (Tovar, 2000).

En la actualidad, Chiapas y la región del Soconusco es una importante región de desarrollo agrícola — local, regional, nacional y de agroexportación, debido a la especialización en monocultivos comerciales y a la producción intensiva de café, banano (plátano), caña, algodón, maíz, soya, papaya y mango ataulfo (Fletes, 2008, 2009; De la Torre González, 2013). En la dinámica económica agrícola fronteriza participan, por un lado, los propios trabajadores agrícolas y, por otro, a manera de empleadores, diversos empresarios, finqueros y ejidatarios - quienes han formado asociaciones de productores agrícolas, y empresas transnacionales, como Chiquita, comercializadora de banano en Estados Unidos.

Entre la región del Soconusco y el suroccidente de Guatemala, a pesar de la existencia de un límite internacional entre ellos, existe una continuidad económica y productiva cafetalera y bananera (Castillo, 1999). Dicha característica se traduce en similitudes de especialización laboral entre las poblaciones de ambos lados del

\footnotetext{
${ }^{1}$ A lo largo del presente texto, se utiliza la noción de co-frontera como una forma de enfatizar la relación entre dos espacios fronterizos, uno en el origen (Guatemala) y otro en el destino (Chiapas, México), a través de prácticas cotidianas que permiten la reproducción social simultánea de las sociedades de ambos lados del límite fronterizo. Dicha noción se considera útil para diferenciar espacios fronterizos en los que no necesariamente existe un contacto intenso y cotidiano entre las sociedades de un lado y otro de un límite fronterizo, cuya vida y reproducción social depende y ocurre en un solo lado de la frontera.

${ }^{2}$ La región del Soconusco agrupa a 15 municipios chiapanecos: Tapachula, Suchiate, Tuxtla Chico, Cacahoatán, Unión Juárez, Huixtla, Escuintla, Acacoyagua, Acapetahua, Frontera Hidalgo, Huehuetán, Mazatán, Metapa, Villa Comaltitlán y Tuzantán.

${ }^{3}$ La región del suroccidente de Guatemala agrupa a seis departamentos: San Marcos, Quetzaltenango, Retalhuleu, Suchitepéquez, Totonicapán y Sololá.

${ }^{4}$ Los datos presentados en este trabajo son una estimación propia con base en la Encuesta sobre Migración en la Frontera Sur de México (Emif Sur), flujo procedente de México a Guatemala, registrado en los puntos de muestreo de Tecún Umán y El Carmen. El valor promedio anual de cruces refiere al periodo entre 2004 y 2018; las estimaciones de 2018 refieren a un total de 143874 desplazamientos laborales (EI Colef et al., 2004, 2018).
} 
río Suchiate, por ello la población guatemalteca se ha incorporado "casi de manera natural" al mercado laboral del Soconusco, incluso algunos de ellos han laborado a lo largo de su vida solo del lado mexicano. ${ }^{5}$

En 2018, de acuerdo con los registros en la Emif Sur (El Colef et al., 2018), los desplazamientos laborales de trabajadores guatemaltecos a la región del Soconusco fueron fundamentalmente para desempeñarse en la agricultura (21.0\%). Cada año entre los meses de octubre a marzo, existe un intenso flujo de trabajadores guatemaltecos agrícolas estacionales que es demandado por las fincas cafetaleras del Soconusco para el corte del grano, a este llamado acuden trabajadores y familias guatemaltecos (Ordóñez, 2007; Castillo \& Vázquez, 2010). En la producción de banano la demanda de trabajadores es constante a lo largo de todo el año debido a que la producción es permanente.

Con el paulatino desarrollo agrícola del Soconusco comenzó el desarrollo urbano, con el cual se inició la incorporación de trabajadores guatemaltecos a la zona urbana (53.7 de los desplazamientos actuales), en los sectores secundario y terciario. ${ }^{6}$ En las zonas urbanas, como Tapachula, Ciudad Hidalgo y Tuxtla Chico, la demanda de trabajadores guatemaltecos se crea desde las familias — usualmente trabajadoras domésticas, mozos, trabajadores de la construcción, jardineros-, y en pequeños negocios locales - como meseras, cocineras, personal de limpieza o para atender al público, cargadores de mercancía, entre otros. Al trabajo para un empleador se le ha añadido el desempeño de trabajos por cuenta propia en actividades como la venta ambulante o el comercio transfronterizo de productos guatemaltecos a Chiapas. ${ }^{7}$ Las actividades desempeñadas en espacios urbanos usualmente son permanentes, por lo que la población guatemalteca se incorpora a dinámicas de alta movilidad transfronteriza u opta por casi establecerse en territorio mexicano.

Una de las principales y sistemáticas características del trabajo guatemalteco en el Soconusco es la precariedad de su incorporación laboral: no se firma un contrato laboral con el patrón o la empresa (99.0\%) y son casi nulas las prestaciones laborales (ya que en menos de $2.0 \%$ de las experiencias laborales se recibe un pago por vacaciones, aguinaldo, servicio de salud, jubilación o ahorro). Sin embargo, una característica relevante del trabajo transfronterizo, e incluso buscada por la población, es recibir apoyos laborales, como alimentación y hospedaje durante el tiempo que se labora en Chiapas. ${ }^{8}$

Como puede observarse en la Figura 1, la dinámica laboral transfronteriza de trabajadores guatemaltecos a la región del Soconusco se intensifica hacia los municipios de Tapachula y Suchiate, lugares de producción cafetalera y bananera

\footnotetext{
${ }^{5}$ De acuerdo con los datos de la Emif Sur (El Colef et al., 2018), en la mitad de los cruces anuales los trabajadores guatemaltecos señalaron que habían trabajado alguna vez en Guatemala, pero en $27.6 \%$ de los casos se señaló que siempre habían trabajado en México, es decir, no tenían experiencia previa en su país de origen.

${ }^{6}$ De acuerdo con la Emif Sur (El Colef et al., 2018), los cruces de guatemaltecos al Soconusco fueron para desempeñarse en los siguientes sectores: edificación (16.4\%), comercio al por menor de textiles, vestido, calzado, abarrotes y alimentos $(10.7 \%)$ y en hogares para el trabajo doméstico $(7.0 \%)$.

${ }^{7}$ En la mayoría de los desplazamientos laborales transfronterizos el trabajador guatemalteco labora para un empleador o patrón $(82.9 \%)$ y en solo $17.0 \%$ se desempeñan como trabajador por cuenta propia (EI Colef, et al., 2018).

${ }^{8}$ De acuerdo con la Emif Sur (El Colef et al., 2018), en $29.9 \%$ de los cruces laborales se recibe alimentación —usualmente dos comidas al día—, y en $23.3 \%$ un lugar donde dormir.
} 
respectivamente; así como territorios en los que se encuentran las principales ciudades fronterizas: Tapachula y Ciudad Hidalgo, en las que se localizan los dos Puentes fronterizos internacionales de la región. ${ }^{9}$ Es de destacar que la ciudad de Tapachula es el lugar en el que converge la vida comercial, residencial, financiera, económica y político-migratoria de la región co-fronteriza Soconusco-suroccidente de Guatemala, por lo que, tanto población mexicana como guatemalteca buscan en este lugar una posibilidad laboral que permita su reproducción social cotidiana.

Figura 1. Región laboral transfronteriza Soconusco-suroccidente de Guatemala

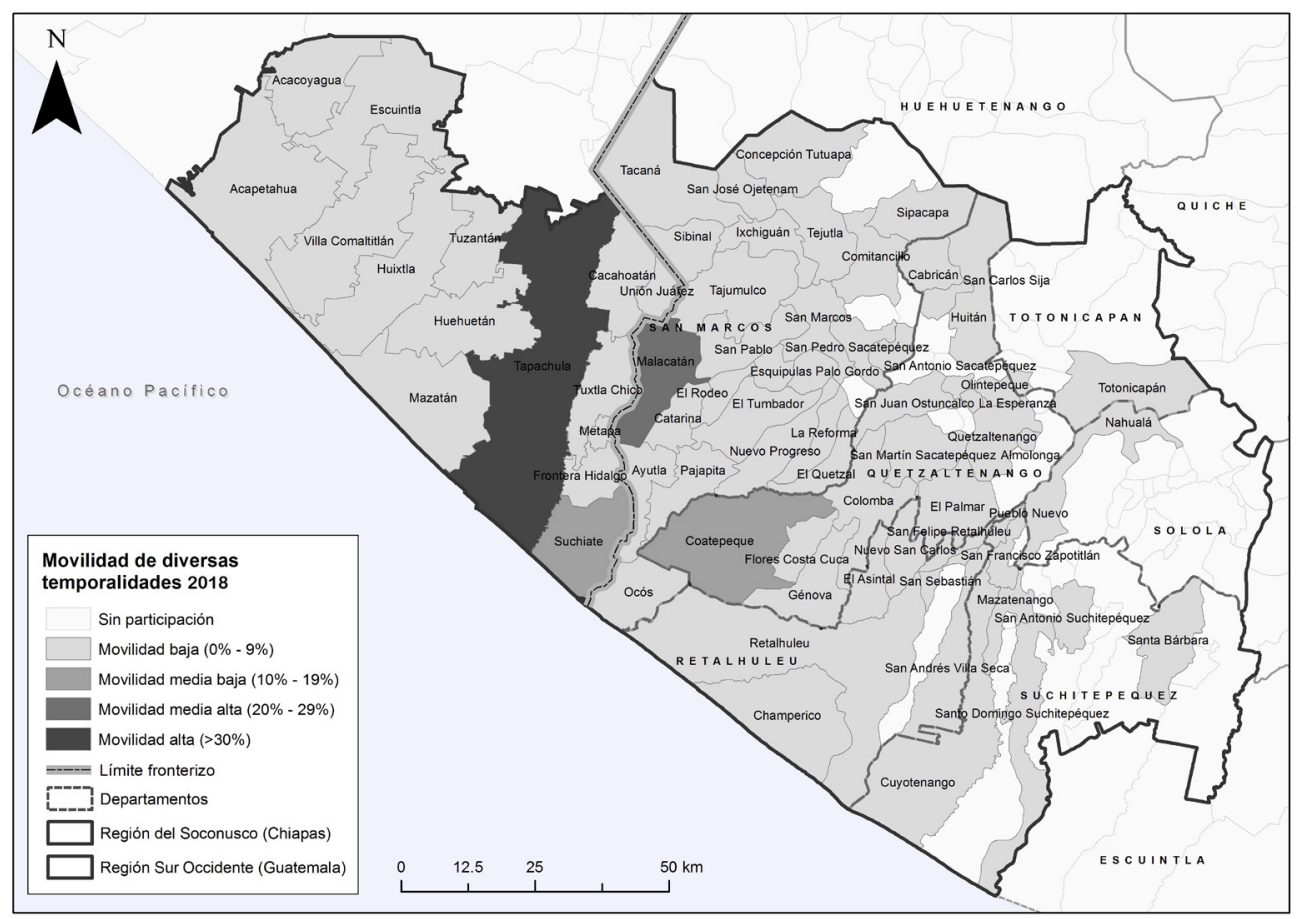

Fuente: Elaboración propia con base en la Emif Sur (El Colef et al., 2018).

En la dinámica laboral transfronteriza México es el territorio de destino laboral de la población guatemalteca, que procede principalmente de los departamentos fronterizos de San Marcos y Quetzaltenango, ${ }^{10}$ de los municipios de Malacatán, Catarina y Coatepeque, lugar en el que mantienen su lugar de residencia habitual y solo se desplazan a trabajar al Soconusco de manera diaria (trabajadores commuters), por una temporada (la cosecha de café), o se mantienen casi de manera estable en territorio mexicano pero con regresos constantes a casa (semanales, quincenales, mensuales, cada tres meses) (Nájera, 2017).

${ }^{9}$ El Puente Internacional Rodolfo Robles conecta las localidades de Ciudad Hidalgo (Suchiate, Chiapas) y Tecún Umán (San Marcos, Guatemala); y el Puente Talismán entre Talismán (Tuxtla Chico, Chiapas) y El Carmen (San Marcos, Guatemala).

${ }^{10}$ De acuerdo con los datos de la Emif Sur (El Colef et al., 2018), 75.2\% de los cruces laborales era de guatemaltecos que residían en el departamento de San Marcos y 16.0\% en Quetzaltenango; pero también hay trabajadores procedentes de otros 13 departamentos guatemaltecos. 
En la frontera Guatemala-México no hay muros ni vallas que limiten o impidan el cruce poblacional, el río Suchiate es el límite fronterizo natural que se cruza por los puentes internacionales o en balsa. Adicionalmente, existe una regulación migratoria que privilegia a la población guatemalteca para el cruce, la estancia y el desempeño de una actividad económica en el Soconusco, con una Tarjeta de Visitante Regional (TVR) ${ }^{11}$ o con una Tarjeta de Visitante Trabajador Fronterizo (TVTF) —para la obtención de este documento se requiere contar con una oferta de trabajo elaborada por el empleador (patrón). ${ }^{12}$

Es así como la movilidad laboral transfronteriza puede hacerse de manera documentada o indocumentada. De acuerdo con los datos de la Emif Sur (El Colef et al., 2018), en menos de la mitad de los cruces laborales transfronterizos, los trabajadores utilizan una TVTF (37.7\%); es más común utilizar una TVR aunque no les autorice a trabajar en territorio mexicano (53.2\%); y son muy pocos los desplazamientos que se hacen de manera indocumentada (menos de 10\%) ya que se corre el riesgo de ser detenido por las autoridades migratorias del Instituto Nacional de Migración (INM) y ser tratado como un migrante en tránsito hacia Estados Unidos —llevado a la Estación Migratoria y devuelto a Guatemala después de varios días.

El estudio de la dinámica laboral transfronteriza entre Chiapas y Guatemala se ha enfocado en la observación segmentada de algún sector económico —como el agrícola cafetalero-, en oficios u ocupaciones específicas — como los trabajadores agrícolas en el café o la caña, las trabajadoras domésticas, los comerciantes transfronterizos o los vendedores ambulantes (Santacruz et al., 2008; Wilson, 2014; Fletes, 2008; García, 2014; Ruíz \& Martínez, 2015). Adicionalmente, se han estudiado grupos específicos de población, como las niñas, niños y adolescentes guatemaltecos que trabajan en Tapachula (López, 2012; Rivera, 2011) y las familias guatemaltecas transfronterizas (Nájera, en prensa); pero también se ha puesto énfasis en las experiencias de la vida cotidiana en las que se vincula la vida laboral con la familiar en este espacio fronterizo, a través de los desplazamientos entre la casa y el trabajo de forma regular, y de cómo dichas prácticas configuran dinámicas y categorías espaciales-temporales específicas (Rojas, 2011; Nájera, 2017).

Sin embargo, a pesar de la histórica llegada de trabajadores guatemaltecos a la región chiapaneca, pocos trabajos han reflexionado respecto a las características y funcionamiento de un posible mercado laboral local de tipo transfronterizo. Al respecto, se encuentran los trabajos de Ordóñez (1993, 2005, 2007), referidos a la integración económica o a la economía informal entre Chiapas y Guatemala. En este escenario, el presente artículo tiene el interés de comprender el mercado laboral local Soconusco-suroccidente, desde una mirada abarcadora laboralmente —en términos de considerar tanto oferta como demanda de trabajadores y transfronteriza- como

\footnotetext{
${ }^{11}$ La TVR permite la entrada y estancia a las cuatro entidades de la frontera sur de México (Chiapas, Tabasco, Campeche y Quintana Roo), de hasta siete días en cada ingreso (durante cinco años renovables), con múltiples entradas y salidas; este documento migratorio lo gestiona la persona guatemalteca en las oficinas el INM en alguno de los puntos fronterizos en México (INM, 2017a). Este documento migratorio no permite trabajar en territorio mexicano.

${ }^{12}$ La TVTF a diferencia de la TVR permite el desempeño de una actividad económica en la frontera sur de México, por ello se requiere de una oferta de empleo suscrita por el empleador o su representante legal (contratista o enganchador); este permiso permite múltiples entradas y salidas del país, durante un año (INM, 2017b).
} 
forma de evitar el nacionalismo metodológico (Wimmer \& Schiller, 2003), al incorporar no solo la región de destino laboral en el Soconusco sino también los territorios de origen en Guatemala.

Para ello, se eligió una estrategia metodológica que permitiera construir el conocimiento desde la experiencia vivida y relatada por uno de los actores más relevantes en este sistema laboral: los trabajadores guatemaltecos. Se buscó heterogeneidad laboral entre los trabajadores guatemaltecos entrevistados, para mostrar un mercado laboral local transfronterizo lo más apegado a la realidad en el Soconusco.

El presente documento está organizado en tres secciones; en la primera se presenta, desde una perspectiva económico-demográfica, un ordenamiento teórico y conceptual reflexivo que permite estructurar los elementos que enmarcan un mercado laboral local fronterizo con dinámicas transfronterizas; posterior a la cual se presenta la estrategia metodológica utilizada en esta investigación. En la tercera sección se presentan los resultados a manera de componentes del mercado laboral transfronterizo entre el Soconusco y el suroccidente de Guatemala: oferta de trabajadores guatemaltecos desde una visión de origen y demanda de trabajadores y las oportunidades laborales en Chiapas desde una visión de destino. Se concluye con algunas reflexiones en torno a los alcances de esta investigación en el contexto de la actual dinámica laboral en la frontera sur de México.

\section{El estudio del mercado laboral en espacios fronterizos: componentes}

La presente investigación parte de estudiar al mercado laboral desde una combinación disciplinaria entre la economía y los estudios de población enfocados en temas laborales y movilidad internacional en espacios fronterizos. Desde el aporte económico, al mercado de trabajo lo definen dos componentes: la oferta de trabajadores y la demanda de trabajadores, los cuales al encontrarse definen las características del trabajo - principalmente el salario. El principal vínculo laboral se establece por la existencia de un empleador que demanda fuerza de trabajo y un trabajador que busca una oportunidad laboral. Como base en Toharia (1983) y Craig y colaboradores (1986), dependiendo de la corriente económica, los supuestos que rigen o intervienen en el vínculo oferta-demanda de trabajadores pueden hacer que se considere la existencia de competencia perfecta en el mercado laboral (en la que todos los actores tienen información completa), que existe racionalidad de los agentes (en la que interviene la maximización de la utilidad) y en el que existen variables que son exógenas a la determinación laboral (como las políticas sociales y culturales) - propuestas principalmente del modelo neoclásico. Para la economía, la oferta de trabajo es el grupo de población económicamente activa dispuesta a trabajar, la cual se define por el tamaño de la población y el tiempo que se desea trabajar, decisiones que dependen del propio individuo (teoría neoclásica) o de la familiar (nueva economía de la migración).

Por su parte, los estudios de mercado laboral realizados desde una visión social han mostrado que existen instituciones, regulaciones y conflictos que no permiten 
un mercado de trabajo "perfecto", ya que demandantes y oferentes de mano de obra actúan con restricciones en contextos sociales, políticos y culturales específicos (Granovetter \& Swedberg, 2001), o están acotados por las estructuras donde actúan, deciden y construyen sus propias "estrategias de empleo" (Della Giusta, 2001), en las que no necesariamente existen actores racionales, ya que hay motivaciones tanto para trabajar como para dejar de hacerlo, para buscar un trabajo del tipo empleadortrabajador (asalariado) o un trabajo no asalariado o independiente. Desde este aporte disciplinario se ha mostrado que las condiciones sociodemográficas de la población, las redes labores y las institucionales intervinientes también son elementos que forman parte de los mercados de trabajo (Granovetter, 1992).

Los estudios de población se han ocupado principalmente por observar a la oferta de trabajadores, en tanto que estudia las condiciones laborales de la población económicamente activa ocupada o fuerza de trabajo. En los estudios de mercado de trabajo desde esta perspectiva disciplinaria se enfatizan las características sociodemográficas de la población, como sexo, edad, posición familiar, escolaridad, tipo de hogar, etapa del ciclo de vida familiar, tamaño de la unidad doméstica y nivel socioeconómico, como elementos que determinan la disponibilidad de mano de obra que conformará la oferta de trabajadores (García, 2011). Se reconoce que la población busca ocupaciones de acuerdo con su disposición en tiempo y movilidad espacial para realizarlos en función de sus características individuales, familiares y contextuales.

Los estudios laborales han mostrado que la población elige (cuando hay opciones) entre trabajos asalariados, que ofrecen mayor estabilidad laboral a pesar de que se subordina a las especificaciones del empleador; y trabajos por cuenta propia o no asalariados, desempeñando alguna profesión o realizando actividades no profesionales - como la compraventa de mercancías, atender micronegocios unipersonales y familiares - en donde se tiene la ventaja de mayor flexibilidad laboral, por lo que es más compatible con otras actividades de la vida diaria - como el trabajo doméstico y el cuidado de los hijos (Pacheco, 2011; Rojas, 2010; Rendón, 2004). Desde la perspectiva poblacional, en el estudio de los mercados de trabajo se incorporan tanto experiencias laborales empleador-trabajador como experiencias de trabajo independiente o por cuenta propia, ya que ambos trabajos remunerados cumplen el propósito de obtener recursos económicos que permitan la reproducción social cotidiana.

Desde la economía, como en los estudios de población, se reconoce que, a un nivel más agregado, los modelos económico-productivo de cada país, región o en un ámbito local, estructuran las posibilidades laborales en cada territorio. En función del tipo de economía local se crean otras formas de incorporación laboral de la población, como las del tipo no subordinadas o independientes. El enfoque sociodemográfico, a pesar del énfasis en la oferta de trabajadores, reconoce que la inserción laboral de la población depende no solo de los intereses de la población dispuesta a trabajar sino también de los intereses de los empleadores en función de sus propias necesidades familiares, comerciales o productivas. Sin embargo, como señala Szasz (1990), en la mayoría de los casos son las características del propio mercado de trabajo local las que definen las condiciones laborales de los trabajadores que se emplean.

Los empleadores definen la demanda de trabajadores determinando el número de trabajadores que requieren, las características de estos y las condiciones laborales bajo las cuales son contratadas. Es así como los empleadores segregan las oportunidades 
laborales de la población (García, 1989) ${ }^{13}$ y, tal vez sin proponérselo, generan formas de desigualdad, exclusión, discriminación e incluso estigmatización, al formar nichos laborales en los que predomina una o varias características sociodemográficas - como el sexo, la edad, la condición étnica o migratoria.

Cuando se estudian mercados laborales en espacios fronterizos, como el que aquí interesa, es necesario incorporar otros elementos sustantivos para su comprensión, como son la propia definición de frontera y movilidad poblacional transfronteriza, la ubicación co-fronteriza de la población en busca de un trabajo remunerado y el lugar en que se encuentran las oportunidades laborales, y la situación fronteriza, en términos del tipo de frontera física y frontera migratorio-administrativa que moldean las posibilidades de movilidad poblacional de un país a otro. A manera de incorporar algunos elementos generales respecto a las nociones de frontera y límite internacional, Rodríguez (2014) señala que la frontera se emplea como una demarcación geopolítica y/o zona de contacto o convivencia entre dos (o más) países, mientras que el límite indica dónde empieza y termina la jurisdicción de un Estado frente a otro(s). En este trabajo, la frontera es el espacio adyacente al límite territorial, poblacional y de vida cotidiana entre un país y otro, en el que interesa observar cómo dos regiones fronterizas se convierten en una región transfronteriza.

De acuerdo con Tapia Ladino (2017), lo transfronterizo se configura a través de la movilidad poblacional. De manera más detallada, la autora considera que la proximidad de poblaciones o ciudades es primordial, pero no condición suficiente; ya que son los intercambios o cruces frecuentes de personas a través de la frontera, con frecuencia independientemente de los litigios bilaterales, lo que da forma a lo transfronterizo; por ello es por lo que esta noción se constituye desde abajo, desde el territorio, por las personas que habitan el territorio. Las distintas prácticas fronterizas convierten a la frontera en un recurso más allá del papel como contención o resguardo; al observar que son las movilidades poblacionales las que unen espacios y ciudades fronterizas, creando la transfrontericidad o lo transfronterizo. En el presente trabajo, dicha característica se verifica y valida en la región Soconusco-suroccidente de Guatemala, a través del panorama proporcionado a través de la Emif Sur.

En los espacios fronterizos es usual que la oferta de trabajadores esté compuesta por la población interesada en trabajar, sea local o del país vecino; espacios donde la condición migratoria moldea las formas de inserción laboral de los trabajadores locales, inmigrantes y trabajadores transfronterizos (Nájera, 2020). La incorporación de población extranjera en el mercado laboral del país vecino puede ser por la insuficiencia de mano de obra local o por la dotación de habilidades laborales específicas que los convierte en una mejor opción.

La regulación migratoria internacional (ONU, 1990) reconoce la existencia de trabajadores migratorios quienes son "toda persona que vaya a realizar, realice o haya realizado una actividad remunerada en un Estado del que no sea nacional", entre los que destacan los trabajadores fronterizos, trabajadores de temporada y trabajadores

\footnotetext{
${ }^{13}$ De acuerdo con García (1989), en los mercados de trabajo se pueden identificar dos tipos de segregaciones: i) la segregación horizontal, cuando dentro del stock de trabajadores existen oportunidades laborales diferenciadas en función de sus características sociodemográficas (como sexo, edad, etnicidad y condición migratoria), que crea ocupaciones u oficios propios de cada grupo poblacional — como sería el caso del trabajo doméstico para las mujeres indígenas migrantes; $y$, ii) la segregación vertical, que refiere a puestos de trabajo de mayor o menor jerarquía, a partir de las mismas características sociodemográficas.
} 
por cuenta propia. Por la relevancia en esta investigación los trabajadores fronterizos o también denominados trabajadores commuters son "todo trabajador migratorio que conserve su residencia habitual en un Estado vecino, al que normalmente regrese cada día o al menos una vez por semana". ${ }^{14}$

En términos de mercado laboral, Morales (2016) y Morales y Castro (2006) muestran que es posible identificar la existencia de dos espacios económico-laborales en torno a un límite internacional: uno que se especializa en la producción directa del valor, en donde se desarrollan las actividades relacionadas con el empleo, y otro en el que se encuentra la fuerza de trabajo, que suele ser el lugar de residencia habitual; ambos espacios fronterizos forman una unidad de producción que sirve de mecanismo de ajuste de los mercados de trabajo locales, cuya demanda de trabajadores en los lugares de destino es abastecida por la oferta de trabajadores de los lugares de origen. Es así como el espacio fronterizo refleja la interconexión de actividades económicas locales y regionales que dan pie a una diversificación laboral en los lugares de destino (Dickens, 2003). $\cdot^{15}$

Para que se lleve a cabo el vínculo entre oferentes de trabajo y demandantes de trabajo, los empleadores activan diversas estrategias como las redes laborales formales a partir de un reclutador, enganchador o contratista, quien consigue la mano de obra requerida; la publicación de la(s) oferta(s) de trabajo por diversos medios y en diferentes lugares, o la presencia en espacios de contratación laboral socialmente reconocidos. Adicionalmente a las redes laborales formales creadas por los empleadores se encuentran las redes laborales informales o redes sociales. Las redes sociales ${ }^{16}$ son un medio indirecto que permite la trasmisión de información acerca de las necesidades de los empleadores u oportunidades laborales, a través de redes de amistad, parentesco y paisanaje. Aunque las redes sociales permiten a los migrantes conseguir un trabajo en el lugar de destino, este puede ser un "empleo posible" y no el "empleo óptimo" para las habilidades y capacidades del trabajador (Canales \& Zlolniski, 2001), e incluso estar restringidos a los empleadores con los que se tenga vínculo. Además, las redes sociales entre migrantes también transmiten información para la vida cotidiana en el lugar de destino (Massey et al., 1994).

En espacios fronterizos, las características del tipo de frontera física y frontera migratorio-administrativa existentes determinan las posibilidades de movilidad poblacional transfronteriza. ${ }^{17} \mathrm{La}$ frontera física refiere a la existencia de elementos

\footnotetext{
${ }^{14}$ La Convención Internacional sobre la Protección de los Derechos de Todos los Trabajadores Migratorios y de sus Familiares (ONU, 1990), en sus artículos 2.1, 2.2a, 2.2b y 2.2h, define a los trabajadores migratorios, los trabajadores fronterizos, y adicionalmente a los trabajadores de temporada que son "todo trabajador migratorio cuyo trabajo, por su propia naturaleza, dependa de condiciones estacionales y solo se realice durante una parte del año"; y los trabajadores por cuenta propia que son "todo trabajador migratorio que realice una actividad remunerada sin tener un contrato de trabajo y obtenga su subsistencia mediante esta actividad, trabajando normalmente solo o junto con sus familiares".

${ }^{15} \mathrm{Al}$ igual que en cualquier mercado laboral, los trabajadores migrantes fronterizos son un grupo poblacional que suele ocupar los niveles más bajos de la estructura o escala laboral y desempeña los empleos de menor calidad (Solís et al., 2018; Acosta et al., 2015); de acuerdo con Pioré (1975), estarían en nichos laborales del sector primario - base de la estructura laboral.

${ }^{16}$ La red social es un sistema abierto, de construcción permanente tanto individual como colectivo, a través del cual existe un intercambio dinámico de integrantes para la potencialización de los recursos (Dabas, 1998).

${ }_{17}$ Pero también la movilidad de mercancías, relevante en términos de mercado de trabajo cuando una de las formas de participación laboral es el comercio de mercancías de un país a otro.
} 
que señalan el límite internacional, sean naturales — como montañas, volcanes, ríos y cordilleras- o artificiales - como muros, vallas, rejas, alambres o mojones-, de los cuales dependen las posibilidades de cruce fronterizo de la población. La frontera migratorio-administrativa es la forma de regulación y el control migratorio para la entrada y la estancia de población al país vecino. Es frecuente que entre países colindantes exista una regulación migratoria diferenciada para la población que reside en zonas fronterizas que se moviliza al país vecino (Pécoud \& De Guchteneire, 2005), usualmente más permisivas respecto al cruce, estancia y actividad a realizar, a diferencia de la población no fronteriza.

Los acuerdos migratorios locales fronterizos se fundamentan en la idea de que la gente mantendrá la residencia habitual en su país de origen, con la posibilidad de entrar y salir al país vecino por razones de compras, paseo o trabajo. Es por lo que en los mercados laborales fronterizos es común la existencia de trabajadores fronterizos, personas que manteniendo su lugar de residencia habitual en el país de origen se desplazan diariamente hacia los lugares donde desempeñan el trabajo remunerado, y conservan una residencia base o única en alguno de los lados de la línea fronteriza (Alegría, 1989). Por ello, las dimensiones de tiempo y costo de los medios de transporte para los desplazamientos entre origen y destino de un lado y otro del límite fronterizo se vuelven también elementos relevantes para la comprensión de los mercados laborales locales.

\section{Metodología}

La presente investigación tiene como fuente de información fundamental el relato de 17 trabajadores guatemaltecos que laboraban en tres de los municipios de la región del Soconusco (Tapachula, Suchiate y Escuintla), de un total de 43 entrevistados. ${ }^{18}$ Se entrevistó a 11 trabajadoras guatemaltecas mujeres y seis varones, quienes laboraban en diferentes sectores de la economía desempeñando distintos oficios o actividades (nueve en el sector agrícola cafetalero y bananero; y ocho en sectores no agrícolas, servicios y construcción, principalmente). Se buscó que los trabajadores participaran de forma distinta en el mercado laboral del Soconusco (12 tenían un empleador o patrón y cuatro eran trabajadores independientes o por cuenta propia) y tuvieran distintas temporalidades de movilidad laboral transfronteriza (cuatro eran trabajadores diarios o commuters, uno con movilidad semanal, tres con movilidad mensual, tres eran trabajadores agrícolas estacionales y seis eran trabajadores casi-permanentes en territorio mexicano con regresos eventuales a Guatemala) (Tabla 1).

\footnotetext{
${ }^{18}$ Se eligieron solo aquellas entrevistas que contenían mayores elementos para la comprensión del mercado laboral transfronterizo del Soconusco-suroccidente de Guatemala, y que mantuvieran la diversidad laboral inicialmente planteada; sin embargo, el resto de las entrevistas fueron relevantes para hacer sólida la comprensión de elementos y dinámicas laborales en general, por lo que aunque no se referencian son parte de la construcción del mercado laboral transfronterizo. Las entrevistas fueron realizadas por la autora de este texto en 2012; debido a que el contexto laboral transfronterizo es persistente en sus características estructurales, las circunstancias económicas, políticas y sociales no cambian sustantivamente con el paso de los años, por lo que el tiempo en que fueron recopiladas las experiencias aquí relatadas se considera que no impacta en la construcción de la dinámica laboral transfronteriza actual, en tanto que aportan elementos generales abstractos que permiten la construcción del mercado laboral local.
} 
Los trabajadores fueron entrevistados en un lado u otro de la frontera GuatemalaMéxico; del lado guatemalteco las entrevistas se realizaron en la casa del trabajador(a) o en alguno de los dos puntos fronterizos de cruce internacional (Tecún Umán o El Carmen) en el momento en que se movilizaban para trabajar en el Soconusco. Del lado mexicano, las entrevistas se realizaron principalmente en el lugar de trabajo, fueran fincas, ejidos, negocios, mercados o en la calle mientras vendían; y algunas se hicieron en lugares de esparcimiento, el domingo por ser el día de descanso, como fue el Parque Miguel Hidalgo u otros espacios de reunión en la ciudad de Tapachula. ${ }^{19}$ En la elección de dialogar con guatemaltecos que trabajaran en el Soconusco para conocer su experiencia en el mercado laboral de la región implicó no considerar la experiencia laboral de aquellos que solo trabajaban del lado guatemalteco, por lo que dichas experiencias no se encuentran presentes en el análisis que aquí se presenta.

Las características y dinámica del mercado laboral del Soconusco se fueron indagado a partir de las siguientes preguntas guía que permitían enfatizar la relevancia de la interacción entre origen y destino laboral: ¿Hay trabajo en Guatemala? ¿Qué características tienen los trabajos en Guatemala? ¿Dónde hay trabajo? ¿Cómo se consigue? ¿Por qué trabaja en Chiapas? ¿Cómo es la vida laboral entre Guatemala y Chiapas? Los resultados aquí presentados fueron complementados y contextualizados con la información recabada en la observación de campo y en la observación participante en los lugares de trabajo en el Soconusco y en la zona de cruce fronterizo Guatemala-México; así como con la información de entrevistas informales realizadas a otros actores clave en esta dinámica laboral transfronteriza, entre ellos empleadores, representantes de asociaciones de productores agrícolas de la región del Soconusco, población local, autoridades migratorias y miembros de organizaciones de la sociedad civil e internacionales que acompañan a la población migrante guatemalteca durante su estancia en la región del Soconusco.

El análisis de los relatos se organizó a partir de las reflexiones teóricas presentadas en el apartado anterior, por lo que se organizó en dos grandes secciones temáticas. La primera refiere al componente oferta de trabajadores, desde la vivencia de los trabajadores en el lugar de origen o de residencia habitual en Guatemala; este subapartado contiene las condiciones laborales en territorio guatemalteco y las motivaciones para cruzar la frontera con México y trabajar en la región del Soconusco. La segunda sección refiere al componente demanda de trabajadores, referida a los empleadores del Soconusco que solicitan trabajadores y, posteriormente, se agregaron las oportunidades de trabajo en esta región fronteriza en la que se incorporan aquellos guatemaltecos que no tienen un patrón o empleador; desde el lugar de destino laboral se muestran las redes laborales formales e informales que figuran como bisagra laboral transfronteriza entre un lado y otro del límite internacional.

\footnotetext{
19 Médicos del Mundo Francia, sede Tapachula, contaba con un espacio de asesoría, apoyo y acompañamiento a migrantes guatemaltecos en Chiapas; en este lugar fueron realizadas algunas entrevistas en domingo, por ser el día de descanso laboral.
} 
Tabla 1: Características de los trabajadores guatemaltecos entrevistados que laboran en Chiapas

\begin{tabular}{|c|c|c|c|c|c|}
\hline Nombre* & $\begin{array}{l}\text { Lugar de } \\
\text { origen en } \\
\text { Guatemala }\end{array}$ & $\begin{array}{l}\text { Lugar de } \\
\text { trabajo en } \\
\text { Chiapas }\end{array}$ & $\begin{array}{l}\text { Temporalidad } \\
\text { del trabajo en } \\
\text { Chiapas }\end{array}$ & $\begin{array}{l}\text { Ocupación } \\
\text { en Chiapas }\end{array}$ & $\begin{array}{l}\text { Posición en el trabajo } \\
\text { en Chiapas }\end{array}$ \\
\hline Álvaro & San Marcos & Escuintla & Estacional & $\begin{array}{l}\text { Trabajador agríco- } \\
\text { la, recolector de } \\
\text { café }\end{array}$ & $\begin{array}{l}\text { Tiene empleador; recibe } \\
\text { pago por destajo, obra o } \\
\text { tarea determinada }\end{array}$ \\
\hline Audelina & San Marcos & Tapachula & $\begin{array}{l}\text { Diaria o } \\
\text { commuting }\end{array}$ & $\begin{array}{l}\text { Comerciante } \\
\text { de comestibles } \\
\text { de Guatemala a } \\
\text { Chiapas }\end{array}$ & $\begin{array}{l}\text { Trabajadora indepen- } \\
\text { diente o cuenta propia } \\
\text { (sin empleador) }\end{array}$ \\
\hline Eliseo & San Marcos & Tapachula & Estacional & $\begin{array}{l}\text { Trabajador agríco- } \\
\text { la, recolector de } \\
\text { café }\end{array}$ & $\begin{array}{l}\text { Tiene empleador; recibe } \\
\text { pago por destajo, obra o } \\
\text { tarea determinada }\end{array}$ \\
\hline Elvia & San Marcos & Tapachula & Mensual & $\begin{array}{l}\text { Trabajadora en el } \\
\text { servicio doméstico }\end{array}$ & $\begin{array}{l}\text { Tiene empleador, recibe } \\
\text { sueldo fijo (asalariado) }\end{array}$ \\
\hline Gabriel & San Marcos & Suchiate & Casi-permanente & $\begin{array}{l}\text { Trabajador agríco- } \\
\text { la en el deshije de } \\
\text { banano }\end{array}$ & $\begin{array}{l}\text { Tiene empleador, recibe } \\
\text { sueldo fijo (asalariado) }\end{array}$ \\
\hline Hilda & San Marcos & Tapachula & Mensual & $\begin{array}{l}\text { Trabajadora en el } \\
\text { servicio doméstico }\end{array}$ & $\begin{array}{l}\text { Tiene empleador, recibe } \\
\text { sueldo fijo (asalariado) }\end{array}$ \\
\hline Idalia & San Marcos & Tapachula & Estacional & $\begin{array}{l}\text { Trabajadora } \\
\text { agrícola, recolector } \\
\text { de café }\end{array}$ & $\begin{array}{l}\text { Tiene empleador; recibe } \\
\text { pago por destajo, obra o } \\
\text { tarea determinada }\end{array}$ \\
\hline Juan & San Marcos & Escuintla & Casi-permanente & $\begin{array}{l}\text { Caporal en una } \\
\text { finca de café }\end{array}$ & $\begin{array}{l}\text { Tiene empleador, recibe } \\
\text { sueldo fijo (asalariado) }\end{array}$ \\
\hline Lupita & San Marcos & Tapachula & Mensual & $\begin{array}{l}\text { Trabajadora en el } \\
\text { servicio doméstico }\end{array}$ & $\begin{array}{l}\text { Tiene empleador, recibe } \\
\text { sueldo fijo (asalariado) }\end{array}$ \\
\hline Martha & San Marcos & Suchiate & $\begin{array}{l}\text { Diaria o } \\
\text { commuting }\end{array}$ & $\begin{array}{l}\text { Recolectora de } \\
\text { protecciones de } \\
\text { banano en la em- } \\
\text { pacadora }\end{array}$ & $\begin{array}{l}\text { Tiene empleador, recibe } \\
\text { sueldo fijo (asalariado) }\end{array}$ \\
\hline Miguel & San Marcos & Suchiate & $\begin{array}{l}\text { Diaria o } \\
\text { commuting }\end{array}$ & $\begin{array}{l}\text { Empacador de ba- } \\
\text { nano en una finca }\end{array}$ & $\begin{array}{l}\text { Tiene empleador; recibe } \\
\text { pago por destajo, obra o } \\
\text { tarea determinada }\end{array}$ \\
\hline Vilma & Santa Rosa & Suchiate & Casi-permanente & $\begin{array}{l}\text { Trabajadora de } \\
\text { limpieza en una } \\
\text { empacadora de } \\
\text { banano }\end{array}$ & $\begin{array}{l}\text { Tiene empleador, recibe } \\
\text { sueldo fijo (asalariado) }\end{array}$ \\
\hline
\end{tabular}

*Los nombres originales fueron cambiados para proteger la identidad de las y los trabajadores entrevistados.

Fuente: Elaboración propia. 


\section{El mercado laboral transfronterizo entre el Soconusco y el suroccidente de Guatemala: una construcción desde la experiencia de los trabajadores guatemaltecos}

Desde una mirada económico-sociodemográfica a continuación se presentan las características y dinámica del mercado laboral local transfronterizo del Soconusco ordenado a manera de oferta y demanda de trabajadores, se hace referencia a las motivaciones económicas y sociales que la población guatemalteca tiene para desplazarse de sus lugares de origen o de residencia habitual hacia Chiapas, así como a las ventajas que se perciben de dicho territorio como espacio de oportunidades laborales. La dinámica laboral aquí presentada refiere a la vivencia de trabajadores guatemaltecos que cotidianamente cruza el río Suchiate para ir a trabajar a la región del Soconusco.

\section{La oferta de trabajadores y el origen residencial: motivaciones para la movilidad laboral transfronteriza}

El trabajo remunerado es uno de los principales medios que permite obtener un ingreso para solventar la vida diaria, por lo tanto, la búsqueda de este lleva a la población a trasladarse a otros territorios. Para los trabajadores guatemaltecos entrevistados, las opciones laborales se encuentran dentro y fuera de Guatemala, como se relata a continuación: "Ir a donde hay trabajo" significa desplazarse hacia otros departamentos guatemaltecos, como la capital del país; cruzar la frontera para ir a la zona fronteriza mexicana y, en algunos casos, pensar en ir a un lugar más lejano como Estados Unidos. ${ }^{20}$ Los destinos laborales se comparan en términos del costo que implica vivir en el lugar durante el tiempo que se trabaja, la variedad de opciones laborales y el contexto en el que se viviría; es usual que la información acerca de dichos destinos laborales sea compartida por las redes sociales, familiares, de vecinos o amigos.

No salir del país es una de las primeras opciones; los trabajadores que relataron tener alguna experiencia laboral en la capital del país, Ciudad Guatemala, reconocen que es un buen destino porque existen amplias posibilidades de encontrar un trabajo, ya que "la gente tiene dinero para pagar". Sin embargo, el principal problema de desplazarse hasta la capital del país es tener que asumir el elevado costo de vivir ahí, además del contexto de inseguridad. Los siguientes relatos dan muestra de ello:

En Guatemala tienes que pagar renta, agua y luz, comprar tu comida, pagar transporte; además hay asaltos, violaciones y muertos; por eso es mejor venir aquí [a Tapachula] (Lupita, 2012).

Allá en Guate [Ciudad de Guatemala] fui a trabajar unos seis meses, pero no me gustó, no me gustó porque allá en la capital hay que pagar la renta

\footnotetext{
${ }^{20}$ Entre el total de trabajadores guatemaltecos entrevistados, solo dos relataron haber tenido alguna experiencia de migración internacional a Estados Unidos o el deseo de tenerla en el futuro; comparado con el desplazamiento fronterizo a Chiapas, los trabajadores reconocen que la migración a Estados Unidos es más costosa, hay que ir más lejos y requiere de ausentarse un mayor tiempo de la familia, la casa y la comunidad.
} 
pues, dónde vivir, la leña, pagar agua para bañarse uno, con lo poco que uno gana... Trabajé en un terreno que estaban construyendo casas, así como por día trabajaba, me daban cuarenta [quetzales] diarios. Lo que yo ganaba lo mandaba para mi casa porque todavía estaba yo [viviendo] con mi hermana. Pero se decidió mi familia también de irse para allá y tuve que arreglar un cuarto de 300 quetzales mensual, y el agua, la luz, todo. [...] Mejor decidí venir otra vez acá [a su casa en San Marcos], porque pensé mejor irme para el otro lado, para acá [a Chiapas], porque aquí gracias a Dios "todo es libre" (Álvaro, 2012).

"Todo es libre" es una expresión usada por los trabajadores guatemaltecos agrícolas para referirse a que durante el tiempo que trabajan en las fincas de café en Chiapas no pagan alimentación, hospedaje y transporte para llegar hasta la finca. La ausencia de gastos de manutención mientras se está en el lugar de trabajo es un beneficio que también se otorga en otros trabajos, como el trabajo doméstico "de planta", en la construcción o a quienes trabajan en pequeños negocios en Tapachula.

Los empleadores ofrecen hospedaje solo si hay un lugar para ello, este puede ser un cuarto o habitación -incluso en "obra negra"- en el que se pueda tener una cama, un catre o una colchoneta; respecto a la alimentación, a veces no se ofrece alimentos, pero sí un lugar para cocinar. Ambos apoyos son percibidos por los trabajadores guatemaltecos como ventajas adicionales al trabajo, independientemente de las condiciones o calidad de estos. Contar con estos "beneficios laborales" puede convertirse en un catalizador para elegir un destino laboral; entre Ciudad de Guatemala y Chiapas, los gastos de manutención suelen ser menores en territorio mexicano -al que se agrega el poco tiempo y bajo costo del desplazamiento fronterizo comparado con el que se requiere para ir hasta la capital del país guatemalteco. ${ }^{21}$

En la zona fronteriza de San Marcos y Quetzaltenango se suele buscar trabajo en las zonas rurales - en las fincas cafetaleras o bananeras de la zona fronteriza, o en las zonas urbanas- como Malacatán o la capital de San Marcos. Los problemas para conseguir un trabajo se refieren al limitado número de ofertas laborales que hay respecto a la cantidad de gente que busca un empleo, al poco tiempo que dura la contratación, a los pocos beneficios laborales que ofrecen (no siempre son empleos asalariados con prestaciones) y, en ocasiones, refieren al mal trato que reciben de los patrones. ${ }^{22}$ Los trabajos disponibles suelen ser del mismo tipo que en Chiapas: trabajadores agrícolas, en la construcción, trabajo doméstico o empleos en pequeños negocios.

La percepción de los entrevistados es que "hay pocos trabajos para tanta gente"; la combinación del factor demográfico con el laboral se muestra al comparar que hay muchos adolescentes, jóvenes y adultos buscando una oportunidad laboral y pocos trabajos en territorio guatemalteco. Cuando se reconoce que existen oportunidades laborales emerge entonces el problema de la temporalidad; ya que se contrata "durante

\footnotetext{
${ }^{21}$ Viajar de San Marcos a Ciudad Guatemala requiere de cinco horas de camino y un costo promedio de \$250 pesos mexicanos; mientras que para cruzar a Chiapas el tiempo promedio es de 30 minutos (desde los municipios cercanos a la frontera) y un costo de 15 pesos para trasladarse a Tapachula.

${ }^{22}$ Martha, trabajadora en una finca de banano en el Soconusco, platica su experiencia:
}

No me gusta que me manden los guatemaltecos. Aquí [en Chiapas] hay más calidad, aquí regañan menos que allá, allá [en Guatemala] le mientan hasta la madre a uno. Allá, sí hay trabajo, en todo. El pago es igual aquí que allá, la diferencia es que allá tienes vacaciones, aguinaldo, el bono y aquí no hay. Es la diferencia de allá (Martha, 2012). 
la época de cosecha", en trabajos de una semana, quince días o un mes, "mientras dura la 'obra' de construcción" o mientras el patrón tiene dinero para pagar un trabajador. Los siguientes relatos dan cuenta de estos vínculos entre cantidad de oportunidades laborales y temporalidad del trabajo:

Ahorita no hay trabajo allá [en Guatemala], ahorita allá dicen que en el mes de mayo van a dar trabajo, pero a unos cuantos. A veces mira uno un trabajo y luego ya no hay, a veces hay trabajo de una semana, quince días y así (Álvaro, 2012).

En Guatemala no se gana nada, no hay trabajo. Allá solo hay trabajos cuando es corte de café, pero el corte de café es por año, entonces hay trabajo. Aquí [en el banano] hay producción toda la vida, no falla la producción, baja un poco a veces en el tiempo de verano, pero cuando viene el invierno ya sube la producción, porque la plantación lo que quiere es agua. Allá nos dan el bono, la bonificación a fin de mes y el aguinaldo, ${ }^{23}$ ahí nos ayuda un poco. Aquí uno tiene que aguantarse [porque no tienen prestaciones]. Pero no estaríamos mejor allá, porque el trabajo está escaso, es limitado el número de personal [que se contrata] y hay muchas personas [que quieren trabajar], por eso nos venimos para acá [a Chiapas] (Gabriel, 2012).

Como señala Álvaro (2012), trabajador agrícola en el café, "uno tiene que cruzar la frontera [Guatemala-México] para trabajar, porque uno come todo el año pues". Para la sobrevivencia de los trabajadores guatemaltecos y sus familiares, ellos alternan trabajos remunerados entre Guatemala y Chiapas, en ocasiones en el mismo sector y actividad u oficio, otras cambiando. Desde las experiencias de los trabajadores entrevistados, la movilidad laboral transfronteriza es una estrategia de vida que queda definida principalmente por los periodos en que no hay trabajo en Guatemala, si es todo el año entonces laboran todo el año del lado mexicano; esta estrategia laboral co-fronteriza (en la que se aprovechan los recursos de cada lado del límite fronterizo) les permite sostenerse económicamente durante todo el año.

En el lado guatemalteco o en el lado mexicano, el trabajo remunerado es el principal medio para la adquisición de bienes y servicios necesarios para la manutención cotidiana en Guatemala o durante el tiempo que se permanece en Chiapas. En ocasiones, del trabajo desempeñado en Chiapas depende la sobrevivencia alimentaria de los trabajadores — principalmente de la población campesina e indígena por las condiciones de pobreza extrema en las que viven-; otras veces es un ingreso que permite mejorar la alimentación, asegurar el acceso a la educación de los hijos, atender necesidades de salud de los miembros de la familia, iniciar un negocio, invertir en construir para ampliar la vivienda, comprar "a pagos" un terreno, entre otros; es así que el trabajo transfronterizo cumple funciones diversas para estas familias. Las precarias condiciones de vida de la población guatemalteca fronteriza siempre motivan el cruce a Chiapas para obtener "un dinero extra", incluso aunque se tenga un empleo formal en Guatemala. Algunos trabajadores aprovechan el periodo vacacional en el trabajo o en la escuela, otros explícitamente solicitan un permiso para aprovechar una mejor oportunidad laboral en el Soconusco, como se observa en los siguientes relatos.

${ }^{23}$ En Guatemala, los trabajadores reciben un bono, una bonificación a fin de mes y aguinaldo, las cuales son prestaciones laborales adicionales al salario o pago fijo. 
Fuimos a pedirle un permiso al encargado de allá [en Guatemala], le agradecimos ¿verdad?, le dijimos que si no podíamos pasar para este lado [a Chiapas] pues lo íbamos a volver a molestar [para volver a trabajar] y que si él nos iba a recibir. Con permiso de él estamos aquí. Pero pensamos también que si no nos gustaba la finca vamos a buscar otra finca por aquí cerca (Idalia, 2012).

Solo cuando estoy de vacaciones donde laboro [en Guatemala], vengo a trabajar a Chiapas; cada año he venido a trabajar aquí, vacaciones de 15 días. Ahorita como ya me van a liquidar [en Guatemala], no sé cuánto tiempo voy a estar aquí (Miguel, 2012).

Pocos son los trabajadores guatemaltecos entrevistados que han tenido un trabajo asalariado, de tiempo completo, con contrato indefinido y en el que reciban todos los derechos laborales instituidos por ley en Guatemala. ${ }^{24}$ Aunque estando en Guatemala esperan tener un trabajo formal, en el traslado laboral al Soconusco no esperan lo mismo, ya que consideran que no tendrán todos los derechos laborales de ley porque son de otro país. Aun así, contar con un trabajo remunerado les permite tener una mejor vida que quedándose solo en Guatemala.

Como se mostró en la primera sección de este texto, casi la mitad de los guatemaltecos que se movilizan a trabajar a Chiapas han iniciado su vida laboral en el Soconusco, esta característica se convierte en la razón para mantenerse trabajando solo del lado mexicano, ya que ahí están sus redes laborales. Audelina, una comerciante de comestibles de Guatemala a México, platica su experiencia:

Aquí [en Guatemala] nadie me conoce y yo no conozco a nadie; hay comerciantes de allá [en Chiapas] y comerciantes de acá, cada quien, de su lado. Yo ya me acostumbré a trabajar de aquel lado [en Chiapas], por eso solo trabajo allá (Audelina, 2012).

Ser trabajador transfronterizo en el Soconusco no siempre es el resultado de una motivación económico-laboral, sino la consecuencia de haber llegado a un nuevo territorio ante la necesidad o el deseo de salir del lugar de residencia habitual. Algunos guatemaltecos que laboran en el Soconusco llegaron a Chiapas por huir de conflictos o violencia intrafamiliar, o por los altos índices de violencia o inseguridad en la comunidad. Los problemas intrafamiliares, entre ellos, los malentendidos, peleas por la posesión de tierras, alcoholismo, agresiones verbales y físicas e incluso amenazas de muerte, disminuyen, se resuelven o simplemente dejan de percibirse cruzando al otro lado del río Suchiate. Hilda, trabajadora doméstica en Tapachula, relata su experiencia:

El hombre [papá de sus dos hijas] quería estar todo el día así molestando, me golpeaba y tomaba mucho. Para quitarme yo del problema por eso estoy aquí [en Tapachula]. "Mejor me voy" dije, "y tal vez así se acaba todo". Si busco trabajo allá en Guate, sí hay, hay mucho trabajo, pero el hombre va a estar ahí, mejor no, por eso me vine acá [a Tapachula] (Hilda, 2012).

\footnotetext{
${ }^{24}$ Entre ellos seguro médico, aguinaldo, bono de productividad, vacaciones y pensión al llegar la edad del retiro.
} 
Cuando la violencia es a nivel comunitario, expresada en robos, asaltos, violaciones, muertes o amenazas, producto de grupos delictivos como la Mara Salvatrucha o Barrio 18, o por la presencia del narcotráfico, la movilidad puede ser de una sola persona o una familia completa, y en ocasiones son los padres quienes les piden a sus hijos adolescentes o jóvenes que se vayan a Chiapas para alejarlos de los grupos delictivos y mantenerlos seguros. Ante estas circunstancias, la población guatemalteca busca un lugar distinto en donde trabajar o incluso establecerse temporalmente, "que esté lejos, pero no tanto"; en estos casos el movimiento fronterizo a Chiapas es una estrategia de resguardo o prevención, como se relata a continuación:

Fíjese que es bonito aquí [en Chiapas], aquí no hay muchos problemas como allá en Guate, allá no puede uno salir a pasear un rato porque ya lo están parando los mareros. Ahorita ya si no les quieres dar [dinero], lo matan a uno, pero aquí no, por eso prefiero estar aquí (Eliseo, 2012).

Yo vine aquí [a Chiapas] porque es mejor no tener mucho dinero, pero así no tienes miedo de que te vengan a matar, por dinero mal habido (Martha, 2012).

Por último, existen otras motivaciones para el cruce fronterizo hacia Chiapas, que no están relacionadas con razones económicas ni de violencia, sino con el interés genuino de conocer un lugar o ciudad distinta al de residencia habitual o de iniciar una vida propia e independiente. En este grupo usualmente están los adolescentes y jóvenes guatemaltecos que señalaron haber llegado a Tapachula porque querían conocer la ciudad más grande en la región transfronteriza México-Guatemala o porque querían iniciar una vida alejados de su familia de origen. El trabajo transfronterizo como objetivo explícito o como resultado de una necesidad de movilidad.

En este escenario, si bien los factores que funcionan como catalizadores de la movilidad transfronteriza de guatemaltecos al Soconusco son diversos, en la participación laboral transfronteriza el factor económico predomina sobre los factores sociales, en tanto que el primero permite resolver necesidades de primer orden como es la manutención económica del propio trabajador o del grupo familiar. En cualquier caso, dentro de un restringido abanico de opciones, la población guatemalteca que eligió Chiapas como su alternativa laboral o de estancia temporal, forman parte de la oferta de trabajadores, mano de obra o población en busca de una oportunidad laboral en el mercado de trabajo local del Soconusco.

\section{La demanda de trabajadores y el destino: oportunidades laborales transfronterizas}

¿Quiénes necesitan trabajadores? ¿Dónde es posible trabajar? En la economía de la región del Soconusco se demandan trabajadores para llevar a cabo las tareas agrícolas y no agrícolas; finqueros, ejidatarios, microempresarios y familias locales fungen como empleadores o patrones no solo de población guatemalteca sino también de mexicana o de otros países que han llegado a vivir a la región fronteriza. La población guatemalteca puede ser contratada por un empleador — quién demanda su fuerza de trabajo-, o ejercer un trabajo por cuenta propia o de manera independiente en el Soconusco; en ambas formas de empleabilidad, el medio más común para conseguir 
un trabajo remunerado del otro lado del río Suchiate son las redes laborales formales e informales transfronterizas que se despliegan en la zona co-fronteriza entre México y Guatemala.

Los trabajadores guatemaltecos entrevistados tienen la imagen de que Chiapas es un territorio con oportunidades laborales, en el que existe una demanda explícita de mano de obra en determinados sectores de la economía — como el agrícola, la construcción y los servicios- o en el que se puede crear su propio trabajo — desde la venta ambulante hasta la instalación de un negocio propio. En el sector agrícola, los trabajadores entrevistados identifican que en decenas de fincas y ejidos productores de café, banano, papaya, caña, mango, limón, rambután, entre otros productos, se contrata a trabajadores por una temporada o de manera casi permanente - por lo que se puede llegar en cualquier época del año y es posible encontrar un trabajo. En el sector urbano, en pequeños y medianos negocios, así como en los hogares, se solicitan trabajadoras domésticas, trabajadores de la construcción y trabajadores en servicios varios.

Como se mencionó en la introducción de esta investigación, Chiapas es el principal productor agrícola de café y plátano (banano) en el país, por ello, decenas de fincas y ejidos en la región requieren de mano de obra a lo largo del año, sean nacionales o extranjeros-vecinos, siempre y cuando "sepan hacer el trabajo". Las fincas de café destacan por la contratación de grandes cantidades de mano de obra en la época de recolección de café que pueden llegar hasta 350 trabajadores ${ }^{25}$ para los meses de octubre a marzo; de manera permanente se requiere un número básico (mínimo) para el mantenimiento de la plantación ${ }^{26}$ y las áreas de la finca —-dormitorios, baños y comedor del área de trabajadores, almácigo, oficinas, bodegas y la casa de los dueños.

En las fincas y ejidos de banano, la demanda de trabajadores es constante en el año, en tanto que la producción del fruto es permanente. Si a dicha característica se le agrega que la unidad productiva se dedica a la exportación del fruto (usualmente a Estados Unidos a través de empresas transnacionales como Chiquita ${ }^{27}$ ), a la demanda de mano de obra se le adicionada que se requiere de una alta productividad. En estos espacios laborales se necesitan trabajadores en más de 18 actividades que diariamente se realizan en las labores del campo (mantenimiento y producción), en las zonas de empaque y en la transportación. ${ }^{28}$ La especialización laboral en estos lugares es muy valorada debido a la especificidad de cada función en el proceso productivo.

Es característico que ante la demanda de trabajadores para sostener la productividad se aprovecha al máximo la mano de obra disponible, por lo que entre más trabajo hay, más

\footnotetext{
${ }^{25}$ Cada unidad productiva de acuerdo con su producción por hectárea y el destino de su producción define el número de trabajadores estacionales que requiere.

${ }^{26}$ Se requieren trabajadores para la recepción y limpieza de café cereza, el despulpado, la remoción de mucílago (fermentación y lavado), el secado, almacenamiento y morteo del café pergamino, clasificación del café oro, empacado y transportación.

${ }^{27}$ Chiquita Brands International es una empresa estadounidense dedicada a la producción de plátano - cuyas plantaciones se encuentran en el sur de México y en Centroamérica (Guatemala, Honduras, Costa Rica y Panamá) - y principal distribuidor en Estados Unidos. Chiquita es la empresa sucesora de la United Fruit Company, creada a finales del siglo XIX.

${ }^{28}$ En labores de campo se trabaja en el riego de herbicida o fertilizantes, en el deshije, saneo o resiembra de plantas, embolse, corte y acarreo de racimos de banano hasta la empacadora. En la zona de empaque, se puede trabajar en la recepción de la fruta, despoje de las protecciones de los racimos, desflore, desmane, clasificación o selección de la fruta, en las actividades de pesar, fumigar, etiquetar, empacar, control de calidad y estibar; adicionalmente están quienes trabajan en las labores de limpieza y empacado de "dedo".
} 
se trabaja y más ganancias se obtienen por parte de los trabajadores guatemaltecos y de los empleadores - aunque por supuesto en su respectiva dimensión. Adicionalmente, cuando el solicitante de un trabajo no tiene experiencia laboral en la producción de banano se le contrata para que apoye en tareas de menor rango, lo que implica una alta rotación de la mano de obra. Vilma, trabajadora en una finca de banano en el Suchiate, es una muestra de ello:

Me mandan a barrer, me mandan a explorar dedo $o^{29}$. Me dicen: "vaya aprendiendo, cuando no haya nada que hacer aquí [en la limpieza] vaya a ver cómo trabajan [en otras áreas] y aprenda, luego usted ya podrá [hacer otra actividad] y ganará más" (Vilma, 2012).

Parece común que desde la experiencia de los trabajadores entrevistados, en las fincas exportadoras de café y banano del Soconusco siempre se requiere de un mayor número de trabajadores que los que tienen. La población guatemalteca que no encuentra trabajo en una finca o ejido se va a otra, o a otra, o a otra, pero encuentra un trabajo; se ofrece para realizar una actividad u otra. En esta búsqueda de trabajo en la zona rural fronteriza chiapaneca es casi seguro que se encuentre una oportunidad laboral, "haciendo una cosa u otra".

Finalmente, la contratación y la condición migratoria se vinculan de manera diferente en el sector cafetalero y bananero. Si bien es cierto que la mano de obra estacional que es contratada en las fincas de café, en su mayoría, cuenta con un documento migratorio laboral expedido por el INM que avala su legal estancia y desempeño de una actividad laboral remunerada y aunque posea un documento de contratación que estipule las condiciones de trabajo, dicho instituto no se encarga de velar por el respeto a los derechos laborales de los trabajadores. En la contratación de trabajadores guatemaltecos en fincas de banano no existe documentación migratoria laboral, por dos razones: el cruce fronterizo se realiza por zonas en las que no hay inspección migratoria y los trabajadores transfronterizos no duermen en el lugar de trabajo - ya que todos son trabajadores diarios o de commuting, por lo que se considera que al salir de la finca o ejido no requieren comprobar su legal estancia en territorio mexicano.

Respecto a los sectores no agrícolas de la economía chiapaneca, los guatemaltecos que llegan a las principales ciudades del Soconusco, como Tapachula, Ciudad Hidalgo o Tuxtla Chico, a buscar una posibilidad laboral en algún negocio o en una casa, buscan dedicarse a la venta de determinado producto $u$ ofrecer cierto servicio a la población local. Los trabajadores guatemaltecos que laboran para un patrón se ocupan en algún negocio atendiendo a la clientela (restaurantes, fondas, papelerías, vulcanizadoras, peluquerías, venta de hielo, de tarjetas de celular o de ropa), en el trabajo doméstico en casas de la zona urbana o apoyando en la construcción de alguna casa o negocio particular. Aunque existen pocos, también hay vendedores ambulantes que trabajan para un patrón, quien les dota de la mercancía que hay que vender y les paga un salario por día.

Los guatemaltecos que trabajan por cuenta propia, sin un patrón o empleador, se desempeñan como vendedores ambulantes independientes de dulces y cigarros por las calles, en la venta de verduras traídas desde Guatemala a las afueras de los mercados

\footnotetext{
29 "Dedo" es la forma de nombrar a un plátano suelto de la penca, los cuales se empacan aparte para la venta en negocios del mercado local. "Explorar dedo" es la labor de recolectar y empacar los plátanos que fueron desprendidos de las pencas.
} 
y supermercados, o de ropa en los parques y plazas. Están también quienes se ofrecen como cargadores de mercancías en mercados, a las afueras de los supermercados o en los límites del río Suchiate; y, finalmente, los comerciantes transfronterizos que movilizan mercancía guatemalteca comestible y no comestible hacia México para la venta a los negocios locales. El último grupo de trabajadores independientes es el que ha instalado su propio negocio en Chiapas para la venta de algún producto o el ofrecimiento de un servicio - un puesto en el mercado, una peluquería, tienda de abarrotes u otro. Este grupo de trabajadores guatemaltecos tiene un vínculo laboral distinto con la sociedad chiapaneca, ya que debe tener relaciones comerciales con los locales para la renta de un local, la contratación de servicios e incluso el pago de impuestos con las instituciones correspondientes.

El trabajo por cuenta propia permite que los trabajadores definan sus propias características laborales como el horario de trabajo, el espacio laboral, ${ }^{30}$ el valor de su producto o servicio, el periodo de trabajo - aprovechando las temporadas de mayor venta que atenúan las de "venta baja", entre otras. Audelina, una comerciante de comestibles de Guatemala a Tapachula, platica su experiencia al respecto:

Entre más se pueda trabajar, se aprovecha. En diciembre es más negocio, ya tiene uno que aprovechar, pues ya hago a veces dos viajes [a Tapachula por semana]. Y como mis hijos ya están de vacaciones, ya me acompañan, ya me aprovecho de ir más temprano, once o doce ya vuelvo del primer viaje. Entonces ya en esos tiempos sí ya me vengo a las ocho de la noche [a Guatemala] (Audelina, 2012).

Cuando la población guatemalteca busca un trabajo del otro lado del río Suchiate, en todos los lugares y modalidades posibles, es decir, en zonas rurales y urbanas, en la diversidad de oficios o actividades a desempeñar dentro de cada sector económico, trabajando para un empleador o sin él, es muy probable que se encuentre alguno, esta práctica da continuidad a la idea de que en Chiapas "siempre hay trabajo". La necesidad de los trabajadores guatemaltecos y la necesidad de los empleadores en el Soconusco encuentran un punto de coincidencia que da forma a un mercado laboral local de tipo transfronterizo. La poca o casi nula participación laboral de la población local en determinados trabajos. ${ }^{31}$ como son el trabajo agrícola y el trabajo doméstico, ha incidido en que la población guatemalteca haya conformado nichos laborales propios, socialmente etiquetados, e incluso estigmatizados, como "trabajos de guatemaltecos". ${ }^{2}$

\footnotetext{
${ }^{30}$ En el caso de los vendedores ambulantes usualmente deben llegar a acuerdos con otros vendedores ya establecidos, especialmente con los que trabajan para un patrón, ya que ellos se despliegan en la zona de mayor venta - el centro de la ciudad de Tapachula.

${ }^{31}$ Diálogos informales con los representantes de la Asociación Agrícola de Productores de Café del Soconusco y la Asociación Agrícola de Productores de Plátano del Soconusco, en los que se señaló que poco más de $90 \%$ de sus trabajadores son de origen guatemalteco.

${ }^{32}$ La exclusividad laboral también se observa en otros trabajos desempeñados por población centroamericana en la región del Soconusco, como es el caso del trabajo sexual adjudicado a las mujeres hondureñas (Fernández, 2012). Desde los estudios laborales a nivel individuo (trayectorias laborales) podrían ofrecerse mayores elementos para distinguir los trabajos que desempeñan locales y extranjeros vecinos a lo largo de la vida en la región, así como identificar que existen trabajos que la comunidad receptora no quiere o no desea realizar, que van convirtiendo al trabajo y a las personas en formas diversas de exclusión (para "los otros").
} 
Para que la demanda de trabajadores desde Chiapas encuentre eco en la oferta de trabajadores guatemaltecos, los empleadores del Soconusco activan redes laborales transfronterizas, creadas por ellos mismos para conseguir el número de trabajadores que requieren, con las características y por el periodo que necesitan. Estas redes son más recurrentes entre los productores agrícolas, aunque existen en otros sectores de la economía; los actores principales son los enganchadores o contratistas, quienes son trabajadores permanentes y de confianza del empleador, usualmente de origen guatemalteco y cuya tarea es conseguir "buenos trabajadores".

Los empleadores cafetaleros y bananeros del Soconusco tienen a "su contratista", quien al ser el vínculo entre la demanda y oferta de trabajadores se ocupa de difundir en Guatemala, a través de medios impresos o audibles, las oportunidades de trabajo que ofrece el empleador en Chiapas; posteriormente traslada a los interesados a la frontera Guatemala-México, realiza a nombre del empleador el trámite de documentación migratoria laboral correspondiente para todos los trabajadores ante el INM y finalmente traslada a los trabajadores guatemaltecos al lugar de trabajo en el Soconusco.

Por lo general, los contratistas o enganchadores optan por iniciar la búsqueda de trabajadores en su municipio de origen $u$ otros ya conocidos, prefieren a trabajadores ya conocidos o "recomendados", aquellos que son de confianza, con experiencia laboral y que "no creen problemas". Si con esta primera elección no se cumple con el número de trabajadores solicitados por el empleador, se recurre a nuevos trabajadores; es así como una red laboral que es inicialmente "cerrada" o acotada a los vínculos del contratista se convierte en una red laboral "abierta", a la que puede acceder cualquier guatemalteco interesado en trabajar.

Aunque estas redes laborales transfronterizas suelen ser formales, porque provienen desde los empleadores del Soconusco, en ocasiones emergen situaciones de imprecisión respecto a las condiciones de contratación de los trabajadores (monto de pago, actividad que realizarán, ubicación de la finca o ejido, beneficios laborales que recibirán); sin embargo, a pesar de ello y ante la necesidad de conseguir un trabajo, deciden irse con quien les promete un trabajo remunerado. En el caso de los trabajadores guatemaltecos que ya cuentan con experiencia laboral transfronteriza previa, en ocasiones, se deja de recurrir a la red laboral del contratista y ellos mismos se desplazan directamente a la finca a pedir un trabajo. Algunas experiencias se plasman en los siguientes relatos:

Uno va a donde lo lleven, uno no sabe dónde queda el lugar, solo sabemos que vamos a trabajar; no nos dicen cuánto nos van a pagar, no sabemos si nos darán una o dos comidas, si de verdad hay camas (Eliseo, 2012).

Los patrones no contratan a cualquiera, a los ya conocidos no les piden "papeles" [documento migratorio] porque son conocidos y confían en ti; si les pidieran "papeles" sería porque no confían en ellos (Álvaro, 2012).

Yo creo que siempre encontramos trabajo porque nos tienen confianza [los patrones y los contratistas], nosotros sabemos mucho del trabajo del café y de ser agricultor, sabemos trabajar. A veces preguntan que si “¿sabes trabajar?” a veces unos dicen que "sí", y ya se quedan (Juan, 2012). 
En ocasiones, los contratistas o enganchadores guatemaltecos no solo cumplen el rol de gestor de trabajo transfronterizo para el empleador, sino también un rol social en la comunidad guatemalteca en la que consiguen a los trabajadores. A solicitud de padres, cónyuges u otros familiares, el contratista se convierte en el encargado, responsable o guardián de adolescentes y jóvenes que se desplazan sin sus padres — particularmente si son mujeres solteras-, o de mujeres casadas que se desplazan sin el cónyuge.

De manera adicional a las redes laborales formales entre demandantes y oferentes de trabajo entre un lado y otro del río Suchiate existen redes laborales informales que cumplen una función similar al difundir información respecto a la existencia de oportunidades laborales en Chiapas, pero a través de vínculos familiares y no familiares —en los que se encuentran amigos, vecinos y paisanos. Estas redes no solo proveen información laboral sino también información básica para solventar la vida en el Soconusco mientras se permanece trabajando - como es conseguir un lugar para vivir, aprender a moverse en la ciudad (transporte local), saber a dónde acudir para acceder a servicios de salud; y también permiten vincular a las personas que están de un lado y otro de la frontera, a través del envío de bienes, dinero o mensajes.

Usualmente las redes familiares son el primer contacto para conseguir un trabajo en Chiapas, a través de padres, tías, sobrinos, primos o cuñados que han tenido alguna experiencia laboral previa o actual del otro lado de la frontera. Los familiares informan, motivan, llevan, instalan e incluso fungen como "responsable o aval" del familiar ante el empleador. La red familiar juega un papel muy importante para aquellos trabajadores que cruzan por primera vez a Chiapas, porque permea el desconocimiento, el miedo y la dependencia de otra persona como apoyo en el cruce, la movilidad fronteriza y la búsqueda de trabajo, como se expresan en los siguientes relatos.

Yo vengo confiada, porque vengo con un conocido, él me dice por dónde cruzar por el río, que el bus, a dónde preguntar, todo (Hilda, 2012).

Había una persona en el parque y me llevó “¿quieres trabajar?”, "sî", dije, "vente", me dijo. A veces da miedo, porque no sabe uno a dónde lo van a llevar, uno no conoce a la persona. Ya cuando le llevan a uno ya conoce la persona, pero todo es que nos llevan y no sé adónde (Elvia, 2012).

En general la primera experiencia laboral en Chiapas se asocia a la trayectoria laboral de padres o familiares con experiencias previas, por ello podría pensarse en una transferencia intergeneracional de trabajo y la perpetuación de los nichos laborales guatemaltecos; aunque también hay quienes se aventuran a explorar por sí solos otros nichos de trabajo, usualmente los hombres y mujeres adolescentes y jóvenes.

La historicidad del fenómeno laboral transfronterizo permite a las personas guatemaltecas que no tienen redes laborales formales o informales acceder a un trabajo en Chiapas, con el solo hecho de cruzar la frontera e ir a los lugares en donde les indican que se contrata a trabajadores o que hay trabajo, como "Casa Roja", oficina del INM en la que se documentan los trabajadores transfronterizos ubicada en el Puente fronterizo Talismán-El Carmen; los parques de las principales ciudades fronterizas, Tecún Umán (del lado guatemalteco) y el Parque Miguel Hidalgo (en la ciudad de Tapachula, Chiapas); acudir a los diversos mercados locales de Tapachula, o a las calles donde se reúnen los vendedores ambulantes, dirigirse directamente a las fincas y ejidos en los márgenes de la carretera que va desde el océano Pacífico hasta la ciudad de Tapachula, en paralelo al río Suchiate. 
Finalmente, resta señalar que de la experiencia vivida por los trabajadores guatemaltecos entrevistados en el mercado laboral transfronterizo del Soconusco se puede deducir que su participación laboral en territorio mexicano no solo permite la reproducción social de ellos y sus familiares, sino también la de los empleadores, familias y personas residentes del lado mexicano que demandan su mano de obra, sus servicios personales o los bienes que comercian. En este escenario, también se puede reconocer la importancia de la actividad económica remunerada que diariamente realizan miles de guatemaltecas y guatemaltecos en territorio mexicano, como la limpieza de las casas y áreas de trabajo, el cuidado de los hijos y de las áreas de producción agrícola cafetalera y bananera, de la construcción de casas y negocios, de atender a los comensales en los restaurantes y a los clientes en lava autos y vulcanizadoras, de vender dulces y alimentos en las calles, de abastecer los negocios de productos guatemaltecos que se consumen en el Soconusco, o de ofrecer sus servicios como peluqueros, estibadores, manicuristas, entre otras. Gabriel, un trabajador del campo bananero, lo expresa de la siguiente manera:

Mi trabajo aquí es deshijando, ver la ubicación de los hijuelos [de la planta del banano], que no se contrapunteen, que vayan a su rumbo, que no se vayan cerrando, separándolos pues, viendo que no se vayan chocando el uno al otro. Yo los enderezo. Es asegurar la producción. Es puro cuidado para la producción. [...] Nosotros somos los que hacemos producir la plantación. Entonces ¿qué ganancia tenemos? No tenemos. Sin nosotros no comen los hijos de los patrones, sin nosotros no hay producción, nosotros somos los que le estamos dando seguimiento (Gabriel, 2012).

\section{Conclusiones}

En el tradicional vínculo entre causas de salida y razones de atracción para la migración, establecidas en las leyes de la migración de Ravenstein (1889) hace más de un siglo, el presente artículo permitió cimentar y articular las principales causas de salida de la población guatemalteca de sus lugares de residencia habitual en la zona fronteriza de Guatemala con las principales razones de atracción a los sitios de destino laboral en la zona fronteriza del lado mexicano. Adicionalmente, para el caso del estudio de mercados laborales localizados en espacios fronterizos se incorporaron elementos sustantivos para su funcionamiento y dinamismo. El primero de ellos es la necesidad de reconocer la importancia de la dimensión poblacional como componente y como perspectiva. Los trabajadores extranjeros vecinos mantienen su lugar de residencia habitual en el país de origen y es a través de la movilidad transfronteriza cotidiana que se incorporan al mercado laboral del país ubicado al otro lado del límite internacional; la población como oferta de trabajadores o mano de obra es un componente del mercado de trabajo relevante que lo sostiene, en este caso, al mercado laboral del Soconusco, donde los trabajadores solo son visibles si se parte de una perspectiva de movilidad poblacional, en la que la movilidad y migración internacional es únicamente otra forma en que la gente residente en zonas fronterizas participa en el mercado de trabajo del país vecino. 
El segundo elemento es la frontera como elemento regulador del mercado laboral transfronterizo. El tipo de frontera internacional entre países vecinos define las posibilidades y potencialidades económico-laborales en la región, en tanto a la existencia o no de muros y vallas y a las formas de regulación y el control migratorio que permiten u obstruyen la incorporación de trabajadores a la zona de demanda de mano de obra, lo que crea dinámicas laborales formales e informales que moldean un mercado laboral local transfronterizo. De un lado de la frontera, la demanda de trabajadores suele ser mayor al número de trabajadores locales dispuestos a laborar, por lo que los trabajadores transfronterizos vecinos complementan o subsanan las necesidades de los empleadores en el destino. Finalmente, los límites fronterizos son elementos sobrellevados por las redes laborales transfronterizas, formales e informales, que vinculan la demanda y oferta de trabajadores y a las sociedades en general de países vecinos.

El tercer elemento es reconocer la predominancia de los motivos económicos en los desplazamientos laborales transfronterizos sobre otros motivos de la movilidad (como la violencia o el interés genuino por conocer otro lugar), por lo que la fuerza de trabajo que se incorpora al mercado laboral local del país vecino tiene como principal motor la búsqueda de un trabajo remunerado que permita mejorar las condiciones de vida del trabajador y sus familiares. En función del contexto socioeconómico guatemalteco, las personas, una vez que valoran las alternativas laborales que estarían a su alcance, eligen como destino laboral incorporarse al mercado de trabajo del Soconusco, todo ello en un marco restringido de opciones locales de una micro región co-fronteriza.

En este escenario, las necesidades de los trabajadores guatemaltecos se conjugan con las necesidades de los empleadores en el Soconusco - sean finqueros y ejidatarios agrícolas de exportación, pequeños empresarios, dueños de negocios o familias-, dando forma a una vida cotidiana que permite la reproducción social conjunta y dependiente de poblaciones adyacentes a un límite fronterizo internacional; aunque, los beneficios económicos sean significativamente más lucrativos para los segundos que para los primeros. No cabría duda de que una parte del desarrollo económico agrícola del Soconusco se basa en la participación guatemalteca como fuerza de trabajo, ya que "sin los trabajadores de origen guatemalteco, nosotros [los empleadores] no podríamos trabajar las fincas, no habría cultivo de café" (Zúñiga, 2009).

A pesar de la histórica relación laboral transfronteriza en esta región, aún es importante seguir dialogando y pensando al respecto, particularmente en los marcos regulatorios laborales y migratorios que permitan reconocer y asegurar los derechos laborales de la población guatemalteca que labora en la frontera sur de México, con propuestas más acordes a la dinámica cotidiana, real y actualizada. En este sentido, resta señalar que en el contexto migratorio regional actual entre México, Centroamérica y Estados Unidos es probable que la frontera sur de México se consolide como un espacio de asentamiento temporal o permanente de diversas poblaciones extranjeras que han llegado en los últimos años a la frontera sur (producto de las caravanas migrantes), aunado a las acciones de política migratoria del gobierno mexicano por retener dichas poblaciones en esta región a través del ofrecimiento de oportunidades laborales locales.

Sin embargo, es relevante diferenciar que los vínculos poblacionales y económicolaborales entre la población local y la población extranjera en esta región es distinta si se es vecino o si no se es, así como de las características socioeconómicas de la población que llega a los lugares de destino. Es de enfatizar que los trabajadores 
guatemaltecos transfronterizos a los que se ha hecho referencia en el presente trabajo se caracterizan por las precarias condiciones de vida — como pobreza, algunos por ser campesinos e indígenas, baja escolaridad ligada a trabajos no agrícolas, características socioeconómicas distintas a otras poblaciones laborales recién llegadas a la región. Por su parte, los vecinos guatemaltecos suelen mantener su lugar de origen como espacio de residencia y acceso a derechos, mientras que los extranjeros no vecinos al establecerse en la zona tienen un acceso a la ciudad y a sus recursos de manera estable (lo que ha generado, de acuerdo con los relatos locales, expresiones de xenofobia, discriminación y exclusión por la población local). En este escenario es plausible pensar al mercado laboral de la región del Soconusco desde una perspectiva de integración laboral y no solo de movilidad laboral transfronteriza.

\section{Referencias}

Acosta, F., Reyes, A. \& Solís, M. (2015). Crisis económica, migración interna y cambios en la estructura ocupacional de Tijuana, México. Papeles de Población, 21(85), 9-46.

Alegría, T. (1989). La ciudad y los procesos transfronterizos entre México y Estados Unidos. Frontera Norte, 1(2), 53-90.

Bartra, A. (1995). Origen y claves del sistema finquero del Soconusco. Revista Chiapas, (1), 1-22.

Canales, A. \& Zlolniski, C. (2001). Comunidades transnacionales y migración en la era de la globalización. Notas de Población, 28(73), 221-252.

Castillo, M. A. (1999). La vecindad México-Guatemala: una tensión entre proximidad y distancia, Estudios Demográficos y Urbanos, 14(1), 193-218.

Castillo, M. A. \& Vázquez, M. (2010). Los inmigrantes guatemaltecos en México: antecedentes históricos y situación actual. En E. Rodríguez (Coord.), Extranjeros en México: continuidades y nuevas aproximaciones (pp. 237-273). Instituto Nacional de Migración/Centro de Estudios Migratorios/DGE Ediciones.

Craig, C., Rubery, J., Tarling, R. \& Wikinson, F. (1986). 5. Economic, social and political factors in the operation of the labour market. En B. Roberts, R. Finnegan \& D. Gallie (Eds.), New approaches to economic life. Economic restructuring: unemployment and the social division of labour (pp. 105-123). Manchester University Press.

Dabas, E. (1998). Redes sociales, familias y escuelas. Paidós.

De la Torre González, A. (2013). De los cafetales del Soconusco a la historia del mango ataulfo 1820-2012 (Colección Soconusco, libro III).

Della Giusta, M. (2001). Redes sociales y la creación de capital social. Trabajo, 2(4), 35-66.

Dickens, P. (2003). Globalization shift, reshaping the global economy map in the 21st century. The Guilford Press.

El Colegio de la Frontera Norte (El Colef), Secretaría del Trabajo y Previsión Social, Secretaría de Gobernación, Consejo Nacional de Población, Unidad de Política Migratoria, Registro e Identidad de Personas, Secretaría de Relaciones Exteriores, Consejo Nacional para Prevenir la Discriminación, Secretaría de Bienestar. (2004). Encuesta sobre Migración en la Frontera Sur de México. www.colef.mx/emif 
El Colegio de la Frontera Norte (El Colef), Secretaría del Trabajo y Previsión Social, Secretaría de Gobernación, Consejo Nacional de Población, Unidad de Política Migratoria, Registro e Identidad de Personas, Secretaría de Relaciones Exteriores, Consejo Nacional para Prevenir la Discriminación, Secretaría de Bienestar. (2018). Encuesta sobre Migración en la Frontera Sur de México. www.colef.mx/emif

Fernández, C. (2012). Tan lejos y tan cerca: Involucramientos transnacionales de inmigrantes hondureños/as en la ciudad fronteriza de Tapachula, Chiapas. Migraciones Internacionales, 6(4), 139-172. http:/ /dx.doi.org/10.17428/rmi.v6i23.729

Fletes, H. B. (2008). La construcción de cadenas agroindustriales de mango en Chiapas. Diversidad y contingencia en la globalización (tesis doctoral). Centro de Investigaciones y Estudios Superiores en Antropología Social. Guadalajara. http://repositorio. ciesas.edu.mx/handle/123456789/31

Fletes, H. B. (2009). La reinvención de una vocación regional agroexportadora. El Corredor Costero de Chiapas. Revista LiminaR. Estudios Sociales y Humanísticos, $7(2), 164-183$.

García, B. (1989, septiembre-diciembre). La importancia del trabajo no asalariado en la economía urbana. Estudios Demográficos y Urbanos, 4(3), 439-463.

García, B. (2011). Las carencias laborales en México: conceptos e indicadores. En E. Pacheco, E. De la Garza \& L. Reygadas (Coords.), Trabajos atípicos y precarización del empleo (pp. 81-113). El Colegio de México.

García, M. (2014). Migraciones laborales en la agroindustria azucarera: jornaleros nacionales y centroamericanos en regiones cañeras de México. Estudios Agrarios, 20(57), 123-148.

Granovetter, M. (1992). Economic action and social structure: The problem of embeddedness. En M. Granovetter \& R. Swedberg (Eds.), The sociology of economic life. Westview Press.

Granovetter, M. \& Swedberg, R. (Eds.). (2001). The sociology of economic life (2a. ed.). Westview Press.

Instituto Nacional de Migración (INM). (2017a, 9 de marzo). ¿Eres guatemalteco o beliceño y deseas visitar los estados de la frontera Sur de México? https://www. gob.mx/inm/acciones-y-programas/eres-guatemalteco-o-beliceno-y-deseas-visitar-los-estados-de-la-frontera-sur-de-mexico

Instituto Nacional de Migración (INM). (2017b, 9 de marzo). ¿Eres guatemalteco o beliceño y deseas trabajar en México? https://www.gob.mx/inm/acciones-y-programas/eres-guatemalteco-o-beliceno-y-deseas-trabajar-en-mexico

López, Y. A. (2012). Niños, niñas y adolescentes: migrantes trabajadores guatemaltecos en la ciudad de Tapachula, Chiapas. Revista LiminaR. Estudios Sociales y Humanísticos, 10(1), 58-74.

Massey, D., Arango, J., Hugo, G., Kouaouci, A., Pellegrino, A. \& Taylor, J. E. (1994) . An evaluation of international migration: The North American case. Population and Development Review, 20(4), 699-751.

Morales, A. (2016). Migraciones laborales y la integración en los mercados de trabajo regionales. En C. Heredia (Coord.), El sistema migratorio mesoamericano. El Colegio de la Frontera Norte/CIDE.

Morales, A. \& Castro, C. (2006). Migración, empleo y pobreza. Facultad Latinoamericana de Ciencias Sociales-Costa Rica. 
Nájera, J. N. (2017). Migración, fuerza de trabajo y familia, elementos en la definición del espacio transfronterizo México-Guatemala. EntreDiversidades. Revista de Ciencias Sociales y Humanidades, (8), 119-150.

Nájera, J. N. (2020). Dinámica de las poblaciones presentes en la frontera México-Guatemala. En S. Giorguli \& J. Sobrino (Eds.), Dinámica demográfica de México en el siglo XXI (vol. 2, pp. 223-264). El Colegio de México.

Nájera, J. N. (en prensa). Más que trabajadores, trabajo transfronterizo y vida familiar de guatemaltecos en Chiapas. El Colegio de México.

Ordóñez, C. E. (1993). Eslabones de frontera: un análisis sobre aspectos del desarrollo agrícola y migración de fuerza de trabajo en regiones fronterizas de Chiapas y Guatemala, México. Universidad Autónoma de Chiapas.

Ordóñez, C. E. (2005). Regiones y tendencias de integración económica fronteriza entre Chiapas y Guatemala. En P. Bovin, Las fronteras del istmo (pp. 249-259). Centro de Estudios Mexicanos y Centroamericanos.

Ordoñez, C. E. (2007). Economía informal y sistema fronterizo en dos espacios locales situados en la frontera de Guatemala con México. Revista de Geografía Agrícola, (38), 85-100.

Organización de las Naciones Unidas (ONU). (1990). Convención internacional sobre la protección de los derechos de todos los trabajadores migratorios y de sus familiares (Adoptada por la Asamblea General en su resolución 45/158, de 18 de diciembre de 1990). Asamblea General.

Pacheco, M. E. (2011). Heterogeneidad y precariedad laboral en los contextos menos urbanizados de México, 1991-2003. En E. Pacheco, E. De la Garza \& L. Reygadas (Coords.), Trabajos atípicos y precarización del empleo (pp. 401-438). El Colegio de México.

Pécoud, A. \& De Guchteneire, P. (2005). Migración sin fronteras: una investigación sobre la libre circulación de personas. Migraciones Internacionales, 3(2), 137-166.

Pioré, M. J. (1975). Notes for a theory of labor market stratification. En R. Edwards, M. Reich \& D. Gordon (Eds.), Labor market segmentation (pp. 125-150). Heath and Co.

Ravenstein, E. G. (1889). The laws of migration. Journal of the Royal Statistical Society, 52(2), 241-301.

Rendón, T. (2004). El mercado laboral y la división intrafamiliar del trabajo. En M. Ariza \& O. De Oliveira (Coords.), Imágenes de la familia en el cambio de siglo (pp. 49-87). IIS-UNAM.

Rivera, C. (2011). El trabajo de niñas, niños y adolescentes guatemaltecos en el Soconusco, Chiapas. En D. Villafuerte \& M. C. García (Coords.), Migración, seguridad, violencia y derechos humanos. Lecturas desde el sur (pp. 257-290). Unicach.

Rodríguez, R. (2014). Epistemología de la frontera. Modelos de sociedad y políticas públicas. Ediciones Eón/ The University of Texas at El Paso/Iniciativa Ciudadana para la Promoción de la Cultura del Diálogo/sipam.

Rojas, M. L. (2011). Haciendo distinciones en la dinámica migratoria. Ecofronteras, (41), pp. 12-15.

Rojas, O. L. (2010). Género, organización familiar y trabajo extradoméstico femenino asalariado y por cuenta propia. Revista Latinoamericana de Estudios de la Familia, 2, 31-50. 
Ruíz, C. E. \& Martínez, G. (2015). Comercio informal transfronterizo México-Guatemala, desde una perspectiva de frontera permisiva. Estudios Fronterizos, 16(31), 149-174. https://doi.org/10.21670/ref.2015.31.a06

Santacruz, E., Pérez, E., Santacruz, G. \& Palacio, V. (2008). La producción platanera y la reorganización del territorio en el Soconusco, Chiapas. Observatorio de la Economía Latinoamericana, (99). http://www.eumed.net/cursecon/ecolat/ $\mathrm{mx} / 2008 / \mathrm{lvlm} . \mathrm{htm}$

Solís, M., Requena, A. T. \& Soriano, R. M. (2018). Mercados de trabajo en regiones fronterizas y no fronterizas en México, 2000-2010. Estudios Fronterizos, 19. https://doi.org/10.21670/ref.1811011

Szasz, I. (1990, enero-marzo). Dimensiones del mercado de trabajo y migración temporal. Un caso en la zona rural del Estado de México. Revista Mexicana de Sociología, 52(1), 151-167.

Tapia Ladino, M. (2017), Las fronteras, la movilidad y lo transfronterizo: Reflexiones para un debate. Estudios Fronterizos, 18(37), 61-80. https://doi.org/10.21670/ ref.2017.37.a04

Toharia, L. (1983). Introducción. En L. Toharia, El mercado de trabajo: Teoría y aplicaciones. Lecturas seleccionadas. Alianza Editorial.

Tovar, M. E. (2000). Extranjeros en el Soconusco. Revista de Humanidades, (8), 29-46.

Wilson, J. (2014). Tirando caña, experiencias laborales-migratorias de adolescentes guatemaltecos cortadores de caña. En C. Rivera (Coord.), Trabajo y vida cotidiana de centroamericanos en la frontera suroccidental de México (pp. 80-97). Centro de Investigaciones y Estudios Superiores en Antropología Social.

Wimmer, A. \& Schiller, N. G. (2003). Methodological nationalism, the social sciences and the study of migration: An essay in historical epistemology. International Migration Review, 37(3), 576-610.

Zúñiga, R. (2009, 25 de noviembre). Seguiremos contratando chapines: cafeticultures tapachultecos. Inforural. https://www.inforural.com.mx/seguiremos-contratando-chapines-cafeticultores-tapachultecos/

Jéssica Natalia Nájera-Aguirre

Mexicana. Doctora en estudios de población por El Colegio de México. Profesorainvestigadora del Centro de Estudios Demográficos, Urbanos y Ambientales de El Colegio de México. Desde metodologías cuantitativas y cualitativas, las líneas de investigación desarrolladas son flujos migratorios entre Centroamérica, México y Estados Unidos; mercado laboral y movilidad poblacional en la frontera MéxicoGuatemala; y, familia y trabajo en espacios fronterizos. Publicación reciente: Nájera, J., Lindstrom, D. \& Giorguli, S. (Eds.). (2019). Migraciones en las Américas. El Colegio de México. 